\title{
Human Rights and Bioethical Considerations of Global Nurse Migration
}

\author{
Felicia Stokes $(\mathbb{D} \cdot$ Renata Iskander
}

Received: 9 January 2020 / Accepted: 16 December 2020 / Published online: 5 July 2021

(C) Journal of Bioethical Inquiry Pty Ltd. 2021

\begin{abstract}
There is a global shortage of nurses that affects healthcare delivery, which will be exacerbated with the increasing demand for healthcare professionals by the aging population. The growing shortage requires an ethical exploration on the issue of nurse migration. In this article, we discuss how migration respects the autonomy of nurses, increases cultural diversity, and leads to improved patient satisfaction and health outcomes. We also discuss the potential for negative impacts on public health infrastructures, lack of respect for cultural diversity, and ethical concerns related to autonomy and justice, including coercion and discrimination. This analysis is written from a rights-based ethics approach by referring to rights held by nurses and patient populations. Nurse migration highlights conflicts between nurses and between nurses and healthcare systems. Increased awareness of ethical challenges surrounding nurse migration must be addressed to enhance the well-being of nurses and patient populations.
\end{abstract}

Keywords Autonomy · Bioethics · Human rights ·

Nurses $\cdot$ Nursing ethics $\cdot$ Migration

F. Stokes $(\bowtie)$

American Nurses Association, 8515 Georgia Avenue, Silver Spring, MD 20910, USA

e-mail: stokes.felicia@gmail.com

R. Iskander

McGill University, 845 Sherbrooke Street West, Montreal, QC

H3A 0G4, Canada

e-mail: renata.iskander@mail.mcgill.ca

\section{Introduction}

Migration of nurses from low-resource or source countries into high-resource or destination countries is common (Galbany-Estragués and Nelson 2016). Migration is defined as the "territorial relocation of people between nation-states" (United Nations Educational, Scientific and Cultural Organization 2017, I10). Currently, the World Health Organization reports a 60 per cent increase in migrant nurses and physicians working in higher income destination countries in the last decade (World Health Organization 2020). Goh and Lopez (2016) reported that in some countries the number of migrant nurses was 20 per cent of the entire nursing workforce. Several high-resource countries (HRCs), such as England, the United Arab Emirates, and Saudi Arabia, are dependent on migrant healthcare professionals to sustain their healthcare systems due to nursing shortages (World Health Organization 2014). In the United States, organizations have employed migrant nurses to reduce nursing shortages for over fifty years (McElmurray et al. 2006). HRCs are unable to educate a sufficient number of nurses to meet the demand for several reasons. In the United Kingdom, reduced government funding has limited the number of nursing student placements, resulting in fewer nurses entering the workforce (Buchan et al. 2015). In the United States, over 80,000 qualified applicants to nursing programmes were turned away in 2019 due to an insufficient number of faculty, clinical sites, and classroom space (AACN 2020). A global shortage of nurses qualified to deliver healthcare currently affects several countries, including 
the United States and European countries but especially low-resource countries (LRCs) (Goh and Lopez 2016; Rosenkoetter, Nardi, and Bowcutt 2017).

An aging global population and increase in chronic health conditions has increased the demand for healthcare professionals, specifically nurses (Pung and Goh 2016). It is estimated that there will be 73 per cent more individuals in the United States over the age of 65 by 2029 , which will increase the need for healthcare professionals providing health services (Haddad et al. 2020). In the United States, an estimated 250,000 nurses entered the workforce in 2019, yet the projected demand in healthcare is double at approximately 550,000, exacerbated by a wave of nurses who are aging out of the profession (Spurlock 2020). Aggressive national and global campaigns have addressed the nursing shortage, but it is projected that by 2025 , the United States alone will require half a million more nurses, and by 2030 , there will be a shortage of 7.6 million more nurses globally to supply the healthcare demand (World Health Organization 2016; Goh and Lopez 2016; Shaffer et al. 2016). It is also predicted that in the United States through 2022, there will be more registered nurse jobs available than any other occupation (Haddad et al. 2020). These projections did not factor in the devastating effects of the COVID-19 pandemic, which has drastically impacted global health and healthcare systems. This global and chronic nursing shortage has led to active recruitment of nurses from low- and middleincome countries to fill the shortage in higher income countries (Efendi, Mackey, Huang, and Chen 2017). Foreign recruitment is considered an immediate strategy to meet the regulatory requirements for patient staffing and to satisfy the needs of an aging population (Efendi et al. 2017). In anticipation of this population increase, it is important to consider the ethical considerations and implications of nurse migration.

Given the global nursing shortage and increase in healthcare demands, migration is expected to be inevitable, and thus it is important to explore this issue from a rights-based approach (Lofters 2012). Migration increases cultural diversity and addresses staffing and employment shortages in healthcare, leading to increased patient satisfaction and health outcomes (Haddad et al. 2020). However, nurse migration may also lead to negative impacts on public health infrastructures, lack of respect for cultural diversity, as well as ethical concerns related to autonomy and justice.
This article explores ethical concerns related to nurse migration using a rights-based ethics approach, which asserts that human rights are afforded to individuals by virtue of their humanity, applies to all persons because they are human, and can thus be referred to as natural rights (Bandman and Bandman 2002). Rights can generally be thought of as morally or legally justifiable claims that can be made upon others or society (Melia 2014) and should be protected and enforced by governments. This approach identifies moral and legal rights and uses them for the purposes of justifying assertions; it recognizes the rules that can be enforced as well as rules that should be followed by society (Melia 2014). Application of the rights-based ethics approach places nurses at the centre of the ethical dilemma to determine how their rights impact ethical decision-making and influence challenges of nurse migration. Since ethics surrounding nurse migration has a global element and laws that govern each country differ, we will refer only to universal or "natural" rights by referring to the Universal Declaration on Bioethics and Human Rights (UDBHR) and the Universal Declaration of Human Rights (UDHR), which applies to all and is commonly incorporated into legal frameworks and constitutions. In order to identify standardized rights that can be applicable internationally to all countries involved in nurse migration, we will be referring to the universal rights documents, the UDBHR and UDHR, which identify fundamental rights that should be universally protected. While some scholars are not convinced of the necessity of the UDBHR when compared to the UDHR, it is helpful for the discussion of nurse migration and the advancement of human rights and health (Wolinsky 2006). The rightsbased ethics approach appeals to the principle of justice ${ }^{1}$ because justice and fairness enhance freedom to exercise autonomous ${ }^{2}$ rights and minimize the risk of

\footnotetext{
${ }^{1}$ Justice is one of the four biomedical ethical principles established by Beauchamp and Childress (2013) that govern bioethics. The term, "fairness," is used to explain justice, which is the "fair, equitable, and appropriate treatment in light of what is due or owed to persons" (Beauchamp and Childress 2013, 250).

${ }^{2}$ Respect for autonomy and autonomous rights involves respect for persons and their self-determination. Beauchamp and Childress (2013) define personal autonomy as "self-rule that is free from both controlling interference by others and from certain limitations such as an inadequate understanding that prevents meaningful choice" (101). Thus, it involves freedom of choice and the ability to exercise rational decision-making capacities. Respecting individuals as autonomous agents requires recognition of their rights to make choices and take actions based on their personal values and beliefs (Beauchamp and Childress 2013).
} 
exploitation, which involves taking unfair advantage of individuals (Bandman and Bandman 2002). Enhanced freedom is important because it involves respecting individuals as autonomous agents and it allows exercising free decision-making. In an unjust society, freedom is difficult to attain because not all rights are afforded to individuals, including the right to choose. Rights are identified by exposing violations of justice and help to define moral standing. Denying the status of rightsholders denies personhood status (Bandman and Bandman 2002). This ethical approach focuses not on justice alone but also on the importance of virtues and duties (Bandman and Bandman 2002). In this context, we will elucidate and consider the benefits and disadvantages of nurse migration, as well as the rights held by nurses and patient populations, including the right to life, the right to choose, and the right to work, among others.

\section{Nursing "Brain Drain”}

This ethical analysis will focus on nurses migrating from LRCs to HRCs, such as the United States, which we will use as a primary example in this article. The shortage of nurses in LRCs is partially a result of a concept called "brain drain," first coined in the 1960s by the Royal Society when discussing the emigration of scientists (Balmer, Godwin, and Gregory 2009). "Brain drain" refers to the migration of highly skilled professionals, usually from LRCs to HRCs (Scott et al. 2004). Migration of healthcare professionals is commonly referred to as "medical brain drain" and contributes to global health crises (Kollar and Buyx 2013). Nurses choose to migrate to destination countries for various reasons, including lack of full-time employment and poor wages in the source country, providing financial support for families in the country of origin, perceived better quality of life for families, intellectual stimulation, improved working conditions, and increased educational opportunities (Efendi et al. 2017; Garner, Conroy, and Bader 2015; Lofters 2012; Rosenkoetter et al. 2017; Sands, Ingraham, and Salami 2020). The problem of the nursing shortage is emphasized in HRCs like the United States, with several strategies and initiatives to try to alleviate the shortage. However, there should be greater focus and discussion on the shortage in LRCs. In Somalia in 2014, there were 0.611 nurses per 10,000 population, 3.109 nurses per 10,000 in Niger in 2014, and 5.004 nurses per 10,000 in Pakistan in 2015, compared to the United States at 85.5 nurses per 10,000 in 2015 (World Health Organization 2019). This unequal distribution of the health workforce has many ethical implications and is worsened by unethical recruitment and poor conditions in source countries (Kollar and Buyx 2013).

The ethics of brain drain has been heavily debated, with arguments stating that the emigration of healthcare professionals has limited the ability for countries to develop health programmes and deliver basic healthcare, especially in countries with epidemics, like HIV/AIDS and Ebola (Scott et al. 2004). In the United States, the shortage of nurses educated in the United States leads to a reliance on recruiting foreign-educated nurses to alleviate the staffing burden. However, migration and recruitment of foreign-educated nurses to HRCs has created an unfair system for LRCs. The process of nurse migration impacts population health and has implications on justice and respect for diversity as well as the potential for loss of autonomy of foreigneducated nurses.

Population-Level Impact of Nurse Migration on Source Countries

Nurses are pivotal in the workforce because they are at the front line providing essential healthcare that has a direct impact on patients (Shaffer, Bakhshi, and Jacobs 2018). Liberalization of trade, globalization, and ease in international travel have created strong economic incentives for outward migration, which benefits source countries (Efendi et al. 2017). While nurse migration can benefit the health structure of source countries as well as destination countries, the impact on the health structure of the source country needs to be considered (Davies 2010). In these countries, the quality of healthcare and patient outcomes are negatively affected (Galbany-Estragués and Nelson 2016). The loss of skilled labour can put increased pressure on the source country's healthcare system, resulting in an increased workload and reduced job satisfaction for those nurses who remain (Brock 2013; Galbany-Estragués and Nelson 2016).

In Poland, it is estimated that 7 per cent of nurses from source countries left for destination countries, despite Poland having the lowest number of nurses in Europe (Szpakowski et al. 2016). Nurses who are educated in Poland are particularly attractive to highresource European countries where the education 
qualifications are automatically recognized (Szpakowski et al. 2016). Poland has one of the lowest number of nurses (5.1) per 1000 inhabitants in the European Union and the migration of nurses in Poland has a negative impact on human resources (Organisation for Economic Cooperation and Development (OECD) 2020). The Polish healthcare system will not be able to meet the future health needs of the aging population partly because of the migration of nurses (Szpakowski et al. 2019).

Also, Indonesia had a significant increase in nurses leaving the country to destination countries from 2008 to 2012. This left the healthcare system severely compromised and unable to deal with public health emergencies such as the 2018 earthquake, which resulted in two thousand deaths (Dianti and McKenzie 2018; Efendi et al. 2017). Yet, this increase in migration is supported by the Indonesia-Japan Economic Partnership Agreement, which facilitates an easy and lucrative path for nurses educated in Indonesia to work in the destination country of Japan (Efendi et al. 2017). Notably, resources for nurse education in source countries have economic significance (Stievano et al. 2017; ten Have 2016). Fifty per cent of the nurses in the IndonesiaJapan agreement utilized Indonesian taxes and resources for education and training, which was subsidized for export to Japan and other countries (Efendi et al. 2017). It is important to recognize that despite the shortage of nurses in Indonesia, this government-supported movement revealed financial earnings of US $\$ 7.35$ billion in remittances sent to the source country by migrant workers in one year alone (Efendi et al. 2017). In the Philippines, global remittances through formal transfers in 2013 totalled US\$35.4 billion and represented 9 per cent of their gross domestic product (Rosenkoetter et al. 2017). Any proposed government-supported migration initiative must analyse the economic, cultural, and feasibility factors associated with implementation. If remittances are allocated that benefit areas such as healthcare, nursing education, or family support, then it could be considered ethically permissible. However, if it is allocated where no benefit is derived for the source country and its citizens, an ethical analysis would be appropriate. Thus, while nurse migration out of these source countries can negatively impact health outcomes for patients, they may incur economic benefits for the source countries.

In considering ethical dilemmas from a rights-based approach, foreign recruitment of nurses by HRCs challenges the UDBHR principle of solidarity, which promotes international cooperation (United Nations Educational, Scientific and Cultural Organization 2006; ten Have 2016). Article 14 of the UDBHR discusses social responsibility and health and states, "The promotion of health and social development for their people is a central purpose of governments that all sectors of society share" (United Nations Educational, Scientific and Cultural Organization 2006, Article 14). The UDBHR identifies a strong public policy for the promotion of health and the social responsibility to all people to ensure health. Social responsibility as a normative ethical principle, resides within a human rights framework that creates conditions for moral obligations (Padela 2017). Social responsibility alone is insufficient to substantiate a country's moral obligation to healthcare. Social responsibility must be accepted and grounded in the cultural norms of the society (Padela 2017). For example, in Muslim nations, stakeholders created a unique and culturally-based Declaration of Human Rights grounded in Islamic law (Padela 2017). This does not suggest that geographic boundaries of states and countries discharge obligations of social responsibility (International Bioethics Committee 2010). However, it is clear that health can no longer be isolated to state or national pockets of interests. Health interests and responsibilities are global and thus involve social relationships beyond geographic boundaries (International Bioethics Committee 2010). Many would argue that some countries have failed to establish healthcare as a moral obligation, evidenced by individuals without access or coverage for healthcare that results in health disparities. In some countries, social accountability citizen groups respond to the healthcare insufficiency and demand greater accountability for failures in these public social services (Lodenstein et al. 2017). Article 14 of the UDBHR calls on stakeholders, governments, and policymakers to provide its citizens with healthcare services and essential medicines that are available, accessible, non-discriminatory, acceptable, and of high quality (Saiz-Alvarez 2016). There is a latent tension between social responsibility and economic benefits, often due to the perception that profits drive a successful society (Brandao et al. 2013). Therefore, we argue that in low-resource countries there is a stronger social responsibility for health towards patients and the economic benefits should not be prioritized.

Article 10 of the UDBHR further strengthens this position by outlining the fundamental requirements of 
equality for all human beings in dignity and rights, which is to be respected for just and equitable care (United Nations Educational, Scientific and Cultural Organization 2006). Equity is justice, and justice is the fair allocation of goods and services, which requires for all to have the right to healthcare access regardless of location (ten Have and Jean 2009). According to the principle of distributive justice, each person must receive an equitable share and each person must receive according to his or her needs (ten Have and Jean 2009). Applying this principle to the migration of nurses, healthcare services should be equitably distributed to those in low- and high-income countries to mitigate disparities in health outcomes and to ensure that public health infrastructures do not suffer from nurse migration (Poudel et al. 2018; ten Have 2016). Overall, there is a social responsibility that countries have to their citizens to ensure adequate resources for healthcare access.

In addition to the negative population-level impact nurse migration has on source countries, there are also potential negative impacts on destination countries, which are important to elucidate. The interests of U.S.-educated nurses and the health of the U.S. population may conflict. Reducing the nursing shortage may improve population health outcomes, yet the increase in foreigneducated nurses can be a financial disadvantage for nurses educated in the United States. For example, it was reported that an increase in foreigneducated nurses by 10 per cent lowers the annual earnings of nurses educated in the United States by 1-4 per cent (Kaestner and Kaushal 2012). Arguably, the increase in foreign-educated nurses leads to an overall improvement in public health because the nursing shortage is further alleviated, leading to fewer errors, as well as lower morbidity and mortality rates (Haddad et al. 2020). The overall improvement in public health should be a priority consideration, and balanced against whether a nurse's right to just remuneration for work (U. N. General Assembly 1948, Article 23) and a nurse's duty of care for patients are being compromised. Similarly, the population health in source countries may be disadvantaged by nurse emigration, although individual nurses emigrating may benefit from increased quality of life and pay increases. Overall, the interests of the population need to be compared to the interests of individual nurses in both LRCs and HRCs.
Discrimination, Promotion of Justice, and Respect for Cultural Diversity

Nurse migration promotes cultural diversity. However, customs and behaviours may need modification in order to gain acceptance by peers in the destination country (Rosenkoetter, Nardi, and Bowcutt 2017). Cultural differences experienced by migrant nurses are found in language, practice, and communication (Garner, Conroy, and Bader 2015). For example, Filipino nurses reported communication challenges with abbreviations and technologies that did not exist in the Philippines (Montayre, Montayre, and Holroyd 2017). Migrant nurses report scrutiny from colleagues and patients because of language and cultural differences, as well as dissimilarities in social and religious practices (Garner et al. 2015; Pung and Goh 2016). Also, migrant nurses from India reported cultural challenges in their own perceptions regarding touching strangers of the opposite sex and working during night hours, which are traditionally associated with promiscuity in their country of origin (Garner et al. 2015). In addition, differences in nursing roles and responsibilities in HRCs compared to LRCs were identified as a barrier by migrant nurses working in destination countries, who are accustomed to subservient roles to physicians and are not involved in healthcare decision-making processes (Montayre, Montayre, and Holroyd 2017; Stievano et al. 2017).

Discrimination in nurse migration is an essential ethical issue to address and has been widely researched and documented (Lie et al. 2014; Pung and Goh 2016). Cultural dissonance, racism, marginalization, discrimination, and exploitation are critical and emerging issues for migrant nurses (Semu 2020). Race and gender are important factors in global migration, as migratory flows often occur in the global South to the North (Semu 2020). Some feminist approaches suggest that women are systemically disadvantaged in migration and are forced into gendered roles of caring such as nursing, domestic, or sex work (Sager 2012). Discrimination based on gender and race are contributing factors of why some migrant nurses wish to return to source countries (Wojczewski et al. 2015). Race continues to be a salient factor in global migration as migrant nurses who are racially marked are undervalued and challenged regarding their skills and abilities (Raghuram 2019; Semu 2020).

Migrant nurses working in destination countries are faced with overt racism, discrimination, disrespect, social isolation, and even threatened physical safety and 
sexual harassment (Garner, Conroy, and Bader 2015; Pung and Goh 2016). For example, nurses reported distrust from their nurse managers and peers when time off was requested to return home to their source countries for a family death (Garner et al. 2015). Filipino nurses reported feeling like outsiders when their previous clinical experiences were not respected, and they were often placed in positions with mentorship from local nurses rather than independent assignments (Montayre et al. 2017). In addition, migrant nurses working in Canada reported discrimination due to ethnicity during the accreditation process to become eligible to work (Pung and Goh 2016). Nurses may also experience discrimination from patients who may refuse treatment from nurses based on ethnicity $(\mathrm{Li}, \mathrm{Nie}$, and $\mathrm{Li}$ 2014). Notably, some healthcare organizations within the United States, including the Mayo Clinic, have begun to address discriminatory and biased incidents against healthcare professionals (Paul-Emilie 2019; Warsame and Hayes 2019).

Fifty per cent of migrant nurses report a negative experience from recruitment and describe unfair work assignments, schedules, and denial of promotion (Pung and Goh 2016; Shaffer et al. 2018). These findings are antithetical to the UDBHR Article 11, which states, "No individual or group should be discriminated against or stigmatized on any grounds, in violation of human dignity, human rights and fundamental freedoms" (United Nations Educational, Scientific and Cultural Organization 2006, Article 11). Also, Article 23 of the UDHR states that every person has the right to "just and favourable conditions of work," which is compromised when migrant nurses experience discrimination in work environments (U.N. General Assembly 1948, Article 23). Protections against discrimination and stigmatization are afforded under the UDBHR and UDHR through considerations of social and legal dimensions and are therefore applicable to migrant nurses working in destination countries (ten Have and Jean 2009).

It should be noted that research within the United States suggests that Filipino nurses reported the lowest discrimination, possibly due to the high levels of social support they receive from their fellow co-workers already working in the United States (Pung and Goh 2016). Marginalization based on gender, race, immigration, and culture is well-understood. Yet many nurses who have migrated to destination countries, especially women, demonstrate resilience and agency by remaining in the profession despite discrimination (Semu
2020). The decision to migrate is an inherently personal one, influenced by cultural, social, and economic influences (Slote 2011). Many migrant nurses enter the nursing workforce below entry-level, such as a nursing assistant or licensed practical nurse, and work their way towards a bachelor's degree in nursing, often while supporting their families and contributing to global remittances (Semu 2020). In addition, Garner et al. (2015) found that migrant nurses from India reported an individual transformation of greater respect from their home countries because of their international experiences. These research findings are important distinctions and suggest culture, support systems, and social integration for migrant nurses must be considered and explored in future research (Pung and Goh 2016).

Article 12 of the UDBHR discusses the respect for cultural diversity and identifies these rights so long as they do not infringe upon human dignity, human rights, and fundamental freedoms (United Nations Educational, Scientific and Cultural Organization 2006). Article 7 of the UDHR also specifies that all are entitled to equal protection against any discrimination (U.N. General Assembly 1948). Globalization of nurses from source countries to destination countries improves the societal perception of nurses at large (Garner et al. 2015). Migrant nurses in destination countries increase the cultural diversity of the nursing profession and the organization where they are employed. One important consideration is whether increasing cultural diversity and teaching lessons on cultural safety takes priority over the health outcomes of patients in source countries that suffer further shortages from nurse migration. In addition to considerations of discrimination and respecting cultural diversity, a relevant dilemma concerns the right to equal pay for equal work (U.N. General Assembly 1948, Article 23). Research suggests variation in whether migrant nurses experience discrimination in pay. It has been reported that there is a small wage premium for migrant nurses, resulting in a lower pay for nurses working in their countries of origin (de Vries et al. 2016). However, other research has shown that migrant nurses are compensated less than those born in the destination country ( $\mathrm{Li}, \mathrm{Nie}$, and Li 2014). As well, nurses migrating from HRCs were paid higher salaries than those who immigrated from LRCs (Li, Nie, and $\mathrm{Li}$ 2014). This conflicting information makes an ethical analysis difficult. In order to satisfy the requirements for respect for human rights, equal opportunities should be granted to nurses from source countries. 
While arguments surrounding the justification for unequal pay may be due to educational standards of source countries, providing unequal opportunities for nurses prevents nurses from attaining the skills learned by nurses educated in destination countries. If migrant nurses are paid less than nurses in destination countries, it could lead to increased unemployment in order to reduce expenditures within the healthcare system.

From a rights-based perspective, it is ethically justifiable for migrant nurses to be paid equally to nurses in the destination country. Yet, this may lead nurses in source countries to emigrate from their home countries to HRCs where they might experience pay increases, thus contributing to this cycle where further foreign nurse recruitment is necessary to alleviate nursing shortages. Overall, discriminatory practices do not follow a rights-based approach, which includes the dilemma of equal pay for equal work, and thus respect for cultures should be promoted to limit marginalization and uphold the principle of justice.

\section{Considerations for Coercion and Human Vulnerability}

Due to the tremendous benefit destination countries may obtain from migrant nurses, aggressive and often unethical recruitment programmes are common, which leads us to a discussion on the right to autonomous choice. Autonomy involves freedom of choice and the ability to exercise rational decision-making capacities. Thus, it is critical to discuss the limits of influence in recruitment of foreign-educated nurses that can lead to diminished autonomy. Coercion involves threatening to make a person worse off than they would be if they do not conform to your preferences and is always unethical. It usually involves an individual agreeing to carry out an action that they do not want to do or prevents an individual from doing something they do want to do (Faden et al. 1986). Coercion is not compatible with the right to autonomy. Coercion requires an acknowledged intent to influence the other person using some kind of threat, but in some circumstances, individuals can unintentionally feel threatened (Faden et al. 1986). It is important to determine whether recruitment practices of foreigneducated nurses diminish autonomy.

There are several reasons why nurses may choose to emigrate and work in HRCs, such as when the quality of living in their home countries is not ideal compared to the destination country. It is important to distinguish between foreign recruitment of nurses and the free choice of nurses to emigrate. Despite emphasis in the UDBHR for social responsibility for health and international cooperation, conflict may arise with articles in the UDHR (U.N. General Assembly 1948). Article 13 of the UDHR states, "Everyone has the right to leave any country, including his own, and to return to his country" (U.N. General Assembly 1948). Article 13 respects the autonomous decision of nurses to freely choose their movement, especially if it will benefit their own wellbeing. It may be beneficial for nurses to move from their home countries because it can increase their quality of life, even if the resulting labour shortage can cause detrimental effects for health systems and outcomes. Thus, the conflicting principles involve the autonomy of nurses and beneficence for patients and health outcomes.

While we should preserve the autonomy of nurses, we should also consider the potential for discriminatory or coercive hiring practices. There is a power imbalance between employees and employers due to a greater need for the employee to gain employment than the employer needing the employee, potentially resulting in undue influence in hiring (Shaffer et al. 2016). Many employers use third-party agencies to recruit nurses from source countries. Many foreign-educated health professionals face unfair treatment, including not being given the opportunity to review contracts that may have unfair terms (Shaffer et al. 2016). Nurses may experience discrimination and unjust working conditions, including mandatory overtime, because of language barriers and fear of retribution (Li, Nie, and Li 2014). This power imbalance and undue influence on already vulnerable nurses, many of whom desperately seek employment and emigration to a high-resource country, can result in coercion and unethical recruitment practices (Shaffer et al. 2016). Nurses seeking employment in destination countries report false promises and working conditions that do not match those listed in the recruitment contract (Shaffer et al. 2016). These experiences describe an implicit violation of Article 8 of the UDBHR, which outlines respect for human vulnerability and personal integrity especially for vulnerable individuals and groups such as migrant nurses who lack familiarity with the destination country (United Nations Educational, Scientific and Cultural Organization 2006).

Unethical recruitment practices can influence nurses who do not voluntarily want to leave their source countries but feel forced to do so. Asymmetries in social, political, and economic power can also lead to coercion 
(ten Have 2016). For example, healthcare facilities in India previously supported a nurse's education through tuition in exchange for a contractual agreement of repayment from the nurse (Garner et al. 2015). This allowed nurses who could not afford tuition an opportunity to receive education in exchange for future work at a facility (Garner et al. 2015). However, in situations where nurses were unable to meet the contractual agreement, a restriction was placed on the nurse's licence (Garner et al. 2015). The withholding of licensure and future employment was considered exploitative and a human rights issue and was condemned by the Indian Nursing Council (Garner et al. 2015). In extreme cases of exploitation, nurses' freedom of movement is restricted and passports or green cards are held by recruiters as collateral (Shaffer et al. 2016).

The UDHR recognizes the autonomy of persons to make decisions, including the decision to migrate to other countries (U.N. General Assembly 1948). Although several nursing codes of ethics outline a primacy to patients, they also identify the right to safe and adequate working conditions, which are often lacking in source countries (American Nurses Association 2015; ICN Code of Ethics 2012; Nursing \& Midwifery Council 2018). Thus, we must also respect the wellbeing of individual nurses who autonomously choose to emigrate to destination countries for a better quality of life. Overall, it is important to consider the principle of autonomy by limiting coercive recruitment practices and promoting and respecting the free choice of movement by nurses.

Future Research and Policy Suggestions

There are several initiatives aimed at eliminating unethical recruitment of healthcare professionals globally. However, reform and enforcement of domestic policies is essential for the protection of unethical recruitment because global policies are often voluntary and unenforceable at the national level (Garner et al. 2015). National efforts to adopt global policies such as The Voluntary Code of Ethical Conduct for the Recruitment of Foreign Educated Nurses to the United States, developed by the American Nurses Association, and the World Health Organization's Global Code of Practice on the International Recruitment of Health Personnel, are complimentary in terms of purpose, content, and objectives (Shaffer et al. 2018). In addition, the International Council of Nurses recently released a position statement titled, International Career Mobility and Ethical Nurse Recruitment. In their position statement, their recommendations include comprehensive regulation for nurses' standards of education and practice, as well as recognizing the freedom of movement, freedom from discrimination, and equal pay for work of equal value (ICN 2019). The ICN also denounces unethical recruitment that leads to exploitation of nurses, recognizes the freedom of choice to migrate and work, and condemns targeted recruitment of nurses from countries with chronic nursing shortages (ICN 2019). Hiring of migrant nurses must include transparency, an explanation of labour rights in the destination country, social support, and integration for migrant nurses and their accompanying families, continuing education on acculturation practices, and screening by employers for knowledge and skill gaps (Efendi et al. 2017; Goh and Lopez 2016). Lastly, continued empirical research on nurse migration is essential to determine trends and inform future policy reform (Goh and Lopez 2016; Stievano et al. 2017).

Based on our analysis, there are several recommendations to improve policy and practice, which have already been suggested by some sources. First, to ensure source countries retain an adequate nursing workforce, it is important to improve working conditions and ensure fair treatment of nurses (Buchan and Sochalski 2004). This can be accomplished through ensuring occupational health and safety and facilitating retention and fair terms for health workers, in addition to eliminating gender-based discrimination, violence, and harassment during recruitment and training (World Health Organization 2014). Development assistance, including financial resources for nursing education, procurement of essential drugs, building hospitals and clinics, and administering public health systems is another avenue for assisting low- and middle-income countries (Dieleman et al. 2019). In addition, recruitment agencies should be regulated for compliance and to limit unethical recruitment practices. Furthermore, labour laws should better align with the United Nations policies to improve these working conditions and dissuade nurses from emigrating from their source countries. In addition, agreements between source and destination countries must be designed to manage nurse migration and ensure benefits for both countries, while maintaining the quality and standard of care for patients in both countries. 
To alleviate nursing shortages in the United States and other countries experiencing a shortage, these countries can meet demands by expanding nursing educational programmes and increasing admissions instead of recruiting from other countries experiencing shortages. Although nurses are required to pass a standard licensure exam, there is still contention as to whether migrant nurses are as skilled and educated as nurses educated in the destination country and to what extent that affects patient care (Kaestner and Kaushal 2012). One way to alleviate this concern is by ensuring standardization of nurses who want to work in the destination country to ensure patient care quality is not compromised. Since education of nurses in each country is adapted to the needs of each country, training is not standardized, thus destination countries should ensure appropriate educational measures before hiring migrant nurses.

Nursing burnout is common in the profession. There is a vicious cycle, which starts with the nursing shortage and is then exacerbated by nurses having to care for patients under difficult working conditions (Hassmiller and Cozine 2006). As a result, more nurses are experiencing burnout and leaving the workforce, which causes further shortage and difficulties in recruiting new nurses (Hassmiller and Cozine 2006). Thus, it is important to ensure fairness and appropriate working conditions to prevent further nursing shortages in all countries. One method to alleviate this burden on nurses is to transfer nurse recruitment from other countries to nurse recruitment within the destination country itself. Data suggests that the nursing shortage in the United States is only present in some states, while other states experience a nursing overage ("Supply and Demand Projections of the Nursing Workforce: 2014-2030" 2017). Thus, instead of focusing on recruitment from other countries, recruitment from other states could alleviate some of the aforementioned ethical dilemmas in addition to adopting other policy strategies.

\section{Conclusion}

Nurse migration is a pivotal health issue with challenges that global communities have been aware of since the 1960s (Rosenkoetter et al. 2017; Stievano et al. 2017). This article outlines the main advantages of nurse migration but also highlights relevant human rights concerns that pertain to the issue. We also discuss negative impacts on source and destination countries, nurses, patients, and healthcare systems. This dilemma highlights the presence of conflicts between foreigneducated nurses and nurses educated in destination countries in addition to conflicts between nurses and healthcare systems. While consideration for patient health outcomes in source countries is important, it should be weighed against the rights and freedoms of nurses. Foreign-educated nurses fill healthcare shortages, increase cultural diversity, and contribute to economic growth and development (Goštautaitè et al. 2018). However, unjust distribution of healthcare services in source countries must be carefully weighed against individual rights to autonomy, freedom, and migration. Increased awareness of coercion and protection from discrimination must be addressed on a global scale to support solidarity and social responsibility and enhance the well-being of nurses and patient populations.

\section{References}

American Association of Colleges of Nursing. 2019-2020 enrollment and graduations in baccalaureate and graduate programs in nursing.

American Nurses Association. 2015. Code of ethics for nurses with interpretive statements. Silver Spring, MD: ANA.

Balmer, B., M. Godwin, and J. Gregory. 2009. The Royal Society and the "brain drain": Natural scientists meet social science. Notes and Records of the Royal Society 63(4): 339-353.

Bandman, E.L., and B. Bandman. 2002. Nursing ethics through the life span. Prentice Hall.

Beauchamp, T.L., and J.F. Childress. 2013. Principles of biomedical ethics. Oxford: Oxford University Press.

Brandão, C., G. Rego, I Duarte, and R. Nunes. 2013. Social responsibility: A new paradigm of hospital governance? Health Care Analysis 21(4): 390-402.

Brock, G. 2013. Is active recruitment of health workers really not guilty of enabling harm or facilitating wrongdoing? Journal of Medical Ethics 39(10): 612-614.

Buchan, J., and J. Sochalski. 2004. The migration of nurses: Trends and policies. Bulletin of the World Health Organization 82(8): 587-594.

Buchan, J., D. Twigg, G. Dussault, C. Duffield, and P.W. Stone. 2015. Policies to sustain the nursing workforce: An international perspective. International Nursing Review 62(2):1621670. https://doi.org/10.1111/inr.12169.

Bureau of Health Workforce. 2017. Supply and demand projections of the nursing workforce: 2014-2030. Rockville, MD: National Center for Health Workforce Analysis.

Davies, S. 2010. Global politics of health. Cambridge, United Kingdom: Wiley.

de Vries, D.H., S. Steinmetz, and K.G. Tijdens. 2016. Does migration "pay off" for foreign-born migrant health workers? An exploratory analysis using the global WageIndicator 
dataset. Human Resources for Health 14(1): 40-40. https://doi.org/10.1186/s12960-016-0136-5.

Dianti, T., and S. McKenzie. 2018. Indonesia quake: More than 5, 000 people could still be missing. CNN World, October 8 . https://edition.cnn.com/2018/10/07/asia/indonesiaearthquake-5000-missing-intl/index.html. Accessed April 14 , 2021.

Dieleman, J.L., A.E. Micah, and C.J. Murray. 2019. Global health spending and development assistance for health. Journal of the American Medical Association 321(21): 2073-2074.

Efendi, F., T.K. Mackey, M.-C. Huang, and C.-M. Chen. 2017. IJEPA: Gray area for health policy and international nurse migration. Nursing Ethics 24(3): 313-328.

Faden, R.R., T.L. Beauchamp, and N.M.P. King. 1986. A history and theory of informed consent. Oxford University Press.

Galbany-Estragués, P., and S. Nelson. 2016. Migration of Spanish nurses 2009-2014. Underemployment and surplus production of Spanish nurses and mobility among Spanish registered nurses: A case study. International Journal of Nursing Studies 63: 112-123.

Garner, S.L., S.F. Conroy, and S. Gerding Bader. 2015. Nurse migration from India: A literature review. International Journal of Nursing Studies 52(12): 1879-1890.

Goh, Y.-S., and V. Lopez. 2016. Job satisfaction, work environment and intention to leave among migrant nurses working in a publicly funded tertiary hospital. Journal of Nursing Management 24(7): 893-901.

Goštautaite, B., I. Bučiūnienè, Ž. Milašauskienė, K. Bareikis, E. Bertašiūtè, and G. Mikelionienè. 2018. Migration intentions of Lithuanian physicians, nurses, residents and medical students. Health Policy 122(10): 1126-1131.

Haddad L.M., P. Annamaraju, and T.J. Toney-Butler. 2020. Nursing shortage. In: StatPearls [Internet]. Treasure Island (FL): StatPearls Publishing. https://www.ncbi.nlm.nih. gov/books/NBK493175/. Accessed April 14, 2021.

Hassmiller, S.B., and M. Cozine. 2006. Addressing the nurse shortage to improve the quality of patient care. Health Affairs 25(1): 268-274.

International Bioethics Committee. 2010. Report of the International Bioethics Committee of UNESCO (IBC) on Social Responsibility and Health. UNESCO.

International Council of Nurses. 2012. The ICN code of ethics for nurses. https://www.icn.ch/sites/default/files/inlinefiles/2012_ICN_Codeofethicsfornurses_\%20eng.pdf. Accessed April 14, 2021.

International Council of Nurses. 2019. International career mobility and ethical nurse recruitment. Geneva, Switzerland.

Kaestner, R., and N. Kaushal. 2012. Effect of immigrant nurses on labor market outcomes of US nurses. Journal of Urban Economics 71(2): 219-229.

Kollar, E., and A. Buyx. 2013. Ethics and policy of medical brain drain: A review. Swiss Medical Weekly 143(4344): 1-8.

Li, H., W. Nie, and J. Li. 2014. The benefits and caveats of international nurse migration. International Journal of Nursing Sciences 1(3): 314-317.

Lodenstein, E., M. Dieleman, B. Gerretsen, and J.E. Broerse. 2017. Health provider responsiveness to social accountability initiatives in low-and middle-income countries: A realist review. Health Policy and Planning 32(1): 125-140. https://doi.org/10.1093/heapol/czw089.
Lofters, A.K. 2012. The "brain drain" of health care workers: Causes, solutions and the example of Jamaica. Canadian Journal of Public Health 103(5): e376-e378.

McElmurry, B.J., K. Solheim, R. Kishi, M.A. Coffia, W. Woith, and P. Janepanish. 2006. Ethical concerns in nurse migration. Journal of Professional Nursing 22(4): 226-235.

Melia, K. 2014. Ethics for nursing and healthcare practice. London: SAGE Publications.

Montayre, J., J. Montayre, and E. Holroyd. 2017. The global Filipino nurse: An integrative review of Filipino nurses' work experiences. Journal of Nursing Management 26(4): 338347.

Nursing \& Midwifery Council. 2018. The code: Professional standards of practice and behavior for nurses and midwives. https://www.nmc.org.uk/standards/code/. Accessed April 14, 2021.

Organisation for Economic Cooperation and Development (OECD). 2020 . Nurses. https://data.oecd. org/healthres/nurses.htm.

Padela, A.I. 2017. Social responsibility and the state's duty to provide healthcare: An Islamic ethico-legal perspective. Developing World Bioethics 17(3): 205-214.

Paul-Emile, K. 2019. How should organizations support trainees in the face of patient bias? American Medical Association Journal of Ethics 21(6): 513-520.

Poudel, C., L. Ramjan, B. Everett, and Y. Salamonson. 2018. Exploring migration intention of nursing students in Nepal: A mixed-methods study. Nurse Education in Practice 29: 95102.

Pung, L.X., and Y.S. Goh. 2016. Challenges faced by international nurses when migrating: An integrative literature review. International Nursing Review 64(1): 146-165

Raghuram, P. 2019. Race and feminist care ethics: Intersectionality as method. Gender, Place \& Culture 26(5 ): 613-637.

Rosenkoetter, M.M., D. Nardi, and M. Bowcutt. 2017. Internationally educated nurses in transition in the United States: Challenges and mediators. The Journal of Continuing Education in Nursing 48(3): 139-144.

Sager, A. 2012. Implications of migration theory for distributive justice. Global Justice: Theory, Practice, Rhetoric 5: 56-70.

Saiz-Álvarez, J.M. (ed). 2016. Handbook of research on social entrepreneurship and solidarity economics. IGI Global.

Sands, S.R., K. Ingraham, and B. Oladunni Salami. 2020. Caribbean nurse migration-A scoping review. Human Resources for Health 18(1): 1-10.

Scott, M.L., A. Whelan, J. Dewdney, and A.B. Zwi. 2004. "Brain drain" or ethical recruitment? Medical Journal of Australia 180(4): 174-176.

Semu, L.L. 2020. The intersectionality of race and trajectories of African women into the nursing career in the United States. Behavioral Sciences 10(4): 69.

Shaffer, F.A., M. Bakhshi, J. To Dutka, and J. Phillips. 2016. Code for ethical international recruitment practices: The CGFNS alliance case study. Human Resources for Health 14(1): 31.

Shaffer, F.A., M. Bakhshi, and A. Jacobs. 2018. Advocating to protect our nurses: Addressing unethical recruitment of foreign-educated nurses. Nursing Administration Quarterly 42(2): 107-114. 
Slote, R.J. 2011. Pulling the plug on brain-drain: understanding international migration of nurses. Medsurg Nursing 20(4): 179.

Spurlock, D. 2020. The nursing shortage and the future of nursing education is in our hands. Journal of Nursing Education 59(6): 303-304.

Stievano, A., D. Olsen, Y. Tolentino Diaz, L. Sabatino, and G. Rocco. 2017. Indian nurses in Italy: A qualitative study of their professional and social integration. Journal of Clinical Nursing 26(23-24): 4234-4245.

Szpakowski, R., G. Dykowska, A. Fronczak, P. Zając, and A. Czerw. 2019. Migrations of nurses and doctors from Poland: Data for the years 2014-2020 based on the sample of the capital city of Warsaw $\gamma$. Archives of Medical Science 15(3): 811-820.

Szpakowski, R., P.W. Zając, G. Dykowska, Z. Sienkiewicz, A. Augustynowicz, and A. Czerw. 2016. Labour migration of Polish nurses: A questionnaire survey conducted with the Computer Assisted Web Interview technique. Human Resources for Health 14(1): 24.

ten Have, H. 2016. Global bioethics: An introduction. New York, NY: Routledge.

ten Have, H., and M. Jean. 2009. The UNESCO universal declaration on bioethics and human rights: Background, principles and application: UNESCO.

U. N. General Assembly. 1948. Universal declaration of human rights. UN General Assembly.

United Nations Educational Scientific and Cultural Organization (UNESCO). 2017. Migrant/Migration. https://wayback. archive-it.org/10611/20171126022441/http://www.unesco. $\mathrm{org} /$ new/en/social-and-human-sciences/themes/internationalmigration/glossary/migrant/. Accessed January 9, 2020.
United Nations Educational Scientific and Cultural Organization (UNESCO). 2006. Universal Declaration on Bioethics and Human Rights. Paris, France: UNESCO Division of Ethics of Science and Technology Social and Human Science Sector.

Wojczewski, S., S. Pentz, C. Blacklock, et al. 2015. African female physicians and nurses in the global care chain: Qualitative explorations from five destination countries. PloS one 10(6): e0129464.

Warsame, R.M., and S.N. Hayes. 2019. Mayo Clinic's 5-Step policy for responding to bias incidents. AMA Journal of Ethics 21(6): 521-529.

Wolinsky, H. 2006. Bioethics for the world. EMBO Reports 7(4): 354-358.

World Health Organization. 2014. A universal truth: No health without a workforce. Global Health Workforce Alliance. World Health Organization. https://www.who. int/workforcealliance/knowledge/resources/GHWA-a universal_truth_report.pdf?ua=1. Accessed April 14, 2021.

World Health Organization. 2016. Global strategy on human resources for health: Workforce 2030. https://apps.who. int/iris/bitstream/handle/10665/250368/9789241511131eng.pdf;jsessionid=60C3E7E41739FA0F30AE65602BC5 DF23?sequence=1. Accessed April 14, 2021.

World Health Organization. 2020. Health workforce-Migration. http://www.who.int/hrh/migration/en/. Accessed April 14, 2021.

Publisher's note Springer Nature remains neutral with regard to jurisdictional claims in published maps and institutional affiliations. 